\title{
Enhanced fatigue damage under cyclic thermo-mechanical loading at high temperature by structural creep recovery mechanism
}

\author{
Nak-Kyun Cho ${ }^{1}$, Haofeng Chen ${ }^{1,2, *}$, James Boyle ${ }^{1}$, Fu-Zhen Xuan ${ }^{2}$ \\ ${ }^{1}$ Department of Mechanical and Aerospace Engineering, University of Strathclyde Glasgow, G1 1XJ, United Kingdom; \\ ${ }^{2}$ School of Mechanical and Power Engineering, East China University of Science and Technology, Shanghai 200237, China \\ *Email: haofeng.chen@strath.ac.uk
}

\begin{abstract}
Creep-cyclic plasticity of a benchmarked holed plate subjected to thermo-mechanical loading is investigated by means of nonlinear finite element analysis. From the analyses, a structural creep recovery response is found within a dwell period, which has serious repercussions on structural integrity. The structural creep recovery can take place by reversing the creep stress in sign during the stress relaxation due to the creep stress redistribution, consequently enhancing unloading plasticity which causes a substantial increase of total strain range within a cycle. Based on this critical observation, further analyses and discussions are provided to investigate the root cause of this precautious structural response. Various cyclic loadings with a dwell at the peak thermal load are analysed to define factors influencing the structural creep recovery mechanism, and to investigate how the mechanism affects the lifetime of the structure. To show the effectiveness of the structural creep recovery mechanism under cyclic loading, Chaboche nonlinear kinematic hardening model is adopted. Limitations of applying elastic follow-up in predicting creep strains and appropriate creepfatigue damage calculation methods are discussed in the presence of this structural creep recovery mechanism. This research work confirms that when a structure experiences the structural creep recovery it can reduce creep damage, nevertheless the structure may experience significant fatigue damage due to creep enhanced plasticity.
\end{abstract}

Keywords: Creep-cyclic plasticity, Stress redistribution, Creep enhanced plasticity, Creep ratchetting

\section{Introduction}

Failure mechanisms of high temperature have been observed in many components in industries such as power generation, aircraft gas-turbine engines, petrochemical process, and so on. The nuclear 
power plant industry requires a significant high level of safety to avoid potential catastrophic disasters during operation. Moreover, new development of future nuclear power station has started to reduce capital costs and meet increasing demands of world energy. These future nuclear power plants will have higher operational temperatures with increased efficiency, while also expected to have more material challenges [1-3].

The high temperature condition induces creep response of materials and has critical effects on structural deformations. In the presence of creep, the response of a structure to cyclic loading changes significantly. The key feature of cyclic loading with creep is the synergistic interaction of cyclic plasticity and creep, which may lead to creep ratchetting. Creep ratchetting can be attributed to "cyclically enhanced creep" and "creep enhanced plasticity". Cyclically enhanced creep is a structural behaviour where the ratchetting is mainly driven by creep strain accumulation with large dwell time. Creep enhanced plasticity is another precautious structural behaviour which creates non-closed hysteresis loop due to a large creep stress relaxation, leading to larger plastic strain accumulation at unloading.

When components such as the reactors or turbine blades are subjected to the complex cyclic loading at the high temperatures, it is difficult to understand its effect on creep stress behaviours in association with variation of creep strains during a creep dwell. Moreover, if the cyclic loading is in nonisothermal condition, it can result in more complicated behaviours of the stress relaxation due to the fact that the components are imposed by internal stresses either tensile stress or compressive stress [4]. This complicated stress relaxation has critical effects on the creep-fatigue damage $[5,6]$. Therefore assessment of the stress relaxation and creep strain evolution within a dwell is important in order to prevent high temperature failures [7-9].

In a monotonic loading test with creep, creep strain tends to increase with an increase of dwell time, stress level, and temperature. However, in a cyclic loading test, a phenomenon of creep strain recovery can be identified after unloading due to its viscoelasticity. Effects of the creep strain recovery are generally negligible in the design analysis of steel structures [10]. Boyle and Spence [11] also have stated that the recovery effects may not be appropriate in design of a comprehensive creep model using the simplified time and strain hardening equations. Recently, Cho and Chen introduced a critical structural creep recovery mechanism which is entirely different from the conventional creep recovery mechanism [12]. This structural creep recovery mechanism can occur by creep enhanced plasticity due to stress redistribution across the structure. The redistribution can take place when a point of the structure has lower stress than elsewhere on the same structure owing to creep. Thus the high stress tends to decrease and the low stress tends to increase. This redistribution can lead to a significant stress relaxation in secondary stress until it reaches to the primary stress level. If the primary stress is imposed on the structure in the opposite sign domain to the secondary stress, 
compressive and tensile creep strains can be developed in a sequence within a dwell, resulting in the structural creep recovery to occur. If a structure experiences this structural creep recovery mechanism, it requires additional consideration of the assessment of structural integrity. The compensated creep strain seems to reduce the risk of creep damage, whereas the creep enhanced plasticity may cause an augmentation in fatigue damage.

The previous work identified the structural creep recovery mechanism using an elastic perfectly plastic model with temperature independence [12]. As an extended research work, this paper describes briefly the previous work, followed by further numerical investigations with practical hardening model such as Chaboche model [13-15] and temperature dependent material properties. Stress-strain interaction under such cyclic thermo-mechanical loading is usually difficult to demonstrate. Therefore, for Section 3.1 and 3.2, the critical structural behaviour is investigated based on simplified material properties such as temperature independent material parameters for a standard grade 316 stainless steel (SS316) and a creep property for Norton law. In Section 3.3, temperature dependent parameters for both mechanical and creep properties are used to present the structural behaviour. As a final validation, for Section 3.4, real elastoplastic hardening parameters are adopted for loading and unloading and Norton-Bailey law is applied for dwell period. Material properties used for the elastoplastic hardening model are taken from real isothermal cyclic testing data for low carbon grade 316L stainless steel (SS316L). The aims of considering different material models and properties in different sections are to have a better and easier understanding and discussion of obtained numerical results, and also to verify the robustness of identified mechanisms under different material models. In the present paper, the influence of the structural creep recovery mechanism on structural integrity is discussed, through a benchmark example of a holed plate. This research also proposes few suggestions to improve current procedures which have been used for prediction of creep strain increment and assessment of creep-fatigue damage, if the structural creep recovery mechanism occurs.

\section{Problem Description and the Finite Element Model}

\subsection{Geometry and Loadings for the Analysis}

Cho and Chen introduced the structural creep recovery mechanism with the benchmarked problem of a holed plate [12]. The identical model is replicated in this paper, and the whole geometry of the structure and a quarter $F E$ meshed model are depicted in Figure 1. The plate has a ratio of 0.2 between diameter $(D)$ of the hole and length $(L)$. The thickness of the plate has a ratio of 0.05 to the length $(L)$. The mechanical tensile load $\left(\sigma_{P}\right)$ acts along horizontal axis and the thermal load is applied to the plate 
as a temperature difference between the inner surface of the hole $(\theta)$ and the outer surface of the plate $\left(\theta_{0}\right)$. The thermal conductivity and expansion coefficient are assumed as $42[\mathrm{~W} / \mathrm{mK}]$ and $1.17 \times 10^{-5}$ $\left[{ }^{\circ} \mathrm{C}^{-1}\right]$ respectively.

Figure 2 depicts the two different loading scenarios acting on the plate at the same time. The temperature at the inner surface of the hole $\theta(t)$ varies from $\theta_{0}$ (ambient temperature assumed as $0^{\circ} \mathrm{C}$ ) to $\theta_{0}+\Delta \theta$ as time function and three load instances follow in order by loading $\left(t_{1}\right), \operatorname{creep}(\Delta t)$, and unloading $\left(t_{2}\right)$.

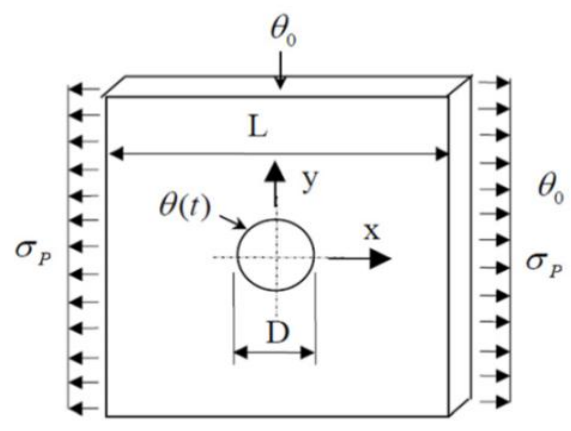

(a)

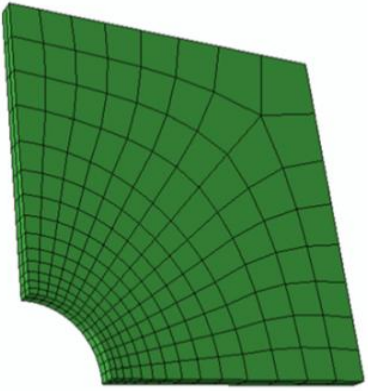

(b)

Figure 1 (a) Geometry of the holed plate and loading conditions and (b) FE meshed model [12].

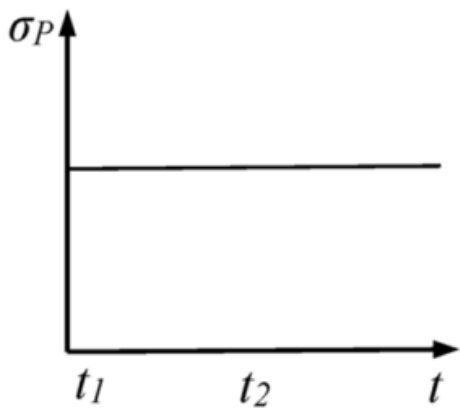

(a)

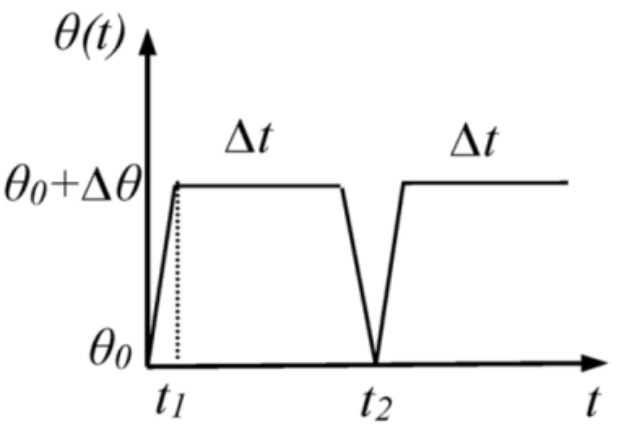

(b)

Figure 2 Loading instances: (a) mechanical loading and (b) thermal loading [12].

Shakedown and ratchet limit boundary curves of the holed plate are produced without the effect of creep by using the Linear Matching Method (LMM) [16] in Figure 3. The mechanical and thermal loads are normalized by a reference uniaxial load $\sigma_{p 0}=100 \mathrm{MPa}$ and a reference temperature $\Delta \theta_{0}=500^{\circ} \mathrm{C}$ respectively. The LMM, that is a direct method, developed by Ponter and Chen [16, 17], is capable of analysing non-linear material behaviour of structures subject to cyclic loadings by a number of iterative linear solutions. In order to investigate the structural creep recovery mechanism, 
six load cases in Figure 3 are selected to perform incremental cyclic analyses considering full creepcyclic plasticity interaction. It is worth noting that without the creep effect, any load cases within the reverse plasticity zone will show an alternating plasticity mechanism.

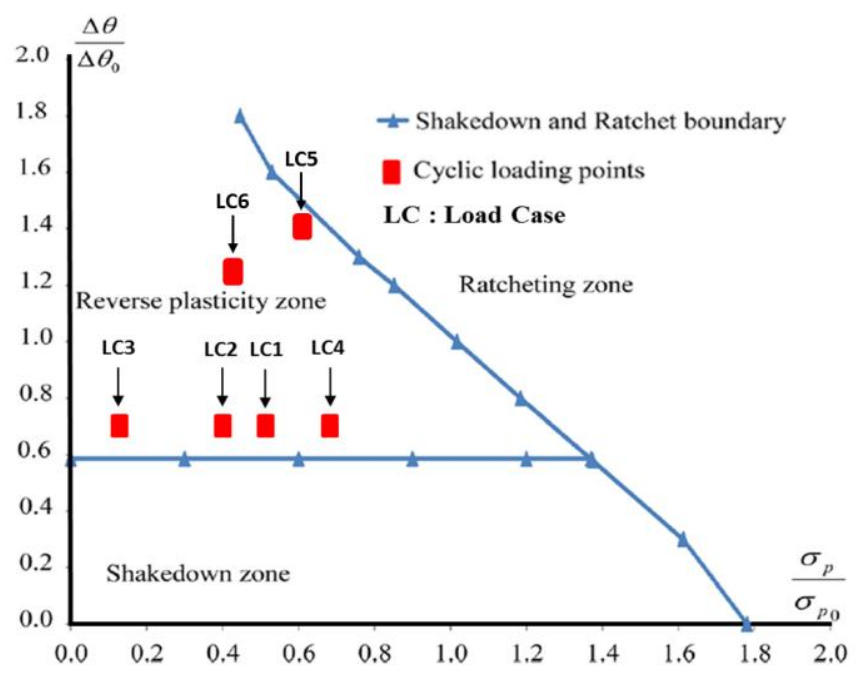

Figure 3 Shakedown and ratchet limit boundaries for the holed plate subjected to the thermomechanical loads and six load cases for investigations of the structural creep recovery mechanism.

\subsection{Material properties and FE model}

It is assumed that the plate is made of a standard grade 316(annealed condition) stainless steel (ASTM A240M) with the following mechanical properties: Young's modulus $(E)=193 G P a$, temperature independent yield stress $\left(\sigma_{y}\right)=205 M P a$, and Poisson's ratio $(v)=0.3$. An elastic perfectly plastic material is assumed for plasticity as a conservative approach to evaluate strains accumulated by the combined cyclic load. The yield surface of the elastic perfectly plastic model can be expressed as

$$
f=J(\hat{\sigma})-\sigma_{y}=0
$$

, where $f$ denotes the function of yield surface, $J(\hat{\sigma})$ and $\sigma_{y}$ are invariant equivalent stress tensor and yield stress respectively. The Norton-Bailey law is widely adopted for calculation of creep strain under tension but there are some studies reporting compressive dwell with the same power law [18, 19]. Therefore creep deformation in the present work is assumed to follow the Norton-Bailey equation within either tensile or compressive dwells:

$$
\dot{\bar{\varepsilon}}^{c}=A \bar{\sigma}^{n} t^{m}
$$

where $\dot{\bar{\varepsilon}}^{c}$ denotes the equivalent creep strain rate, $\bar{\sigma}$ is the effective von-Mises stress, $t$ is the dwell time, and $A, n$, and $m$ are temperature dependent material constants of creep. To simplify the analyses, 
following creep material constants are assumed: $A=5.86 \times 10^{-15}\left[\mathrm{MPa}^{-1} h^{-1}\right]$ at temperature of $500^{\circ} \mathrm{C}$, $n=5$ as a typical value for austenitic steel, $m=0$ so the Norton-Bailey law is reduced to simple Norton's law.

For a quarter model of the plate, twenty-node quadratic hexahedral elements with reduced integrations (C3D20R) are used. Mesh size and its quality are assessed, which confirmed less than $1 \%$ resultant stress and strain deviations as number of mesh increases up to 50\%. Symmetry boundary conditions are applied, and outer surfaces of the plate are constrained to maintain a plane condition. In order to implement the thermal gradient, the adiabatic condition is applied to outer surfaces of the plate. Temperature difference $\Delta \theta_{0}=500^{\circ} \mathrm{C}$ between the centre hole and the outer surfaces are applied as a thermal stress and the mechanical load $\sigma_{p}=100 \mathrm{MPa}$ is imposed as shown Figure 1(a). Thermal conductivity of $25.2[\mathrm{~W} / \mathrm{mK}]$ and expansion coefficient of $1.75 \times 10^{-5}\left[{ }^{\circ} \mathrm{C}^{-1}\right]$ are applied. To find a saturated stress-strain cycle, step-by-step ( $S B S$ ) analysis is performed using commercial software Abaqus. For the $S B S$ analysis, sixty individual load steps are created, which is in total twenty cycles of three load steps corresponding to loading, creep, unloading respectively.

\section{Results and Parametric Studies}

\subsection{Investigation of the Structural Creep Recovery Mechanism}

To account for the structural creep recovery mechanism, an $S B S$ analysis is performed with load case $1\left(\Delta \theta=0.7 \Delta \theta_{0}\right.$ and $\left.\sigma_{p}=0.5 \sigma_{p 0}\right)$ for a dwell time of $200 \mathrm{hrs}$. Equivalent von-Mises stress distributions for each load instance and effective creep strain increment at creep dwell are depicted in Figure 4.

During loading instance, effective stresses are distributed as shown in Figure 4(a). Within creep instance, the effective stresses reduce significantly as shown in Figure 4(b) due to the creep stress relaxation. The effective stresses distribution across the holed plate after unloading instance is presented in Figure 4(c), where the critical areas become yield due to reverse plasticity taking place during unloading. We can see peak stresses imposed along with the centre hole area at loading, and then the peak stress shifted to the top of the hole at creep. Consequently, in Figure 4(d), peak creep strain occurs at the same point as Figure 4(b), where the peak stresses take place. 


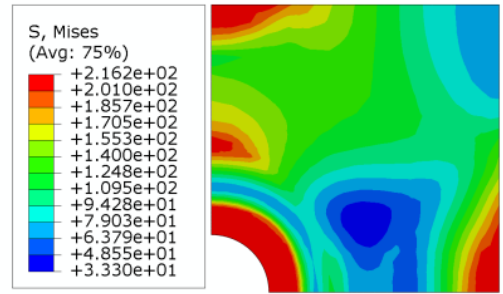

(a)

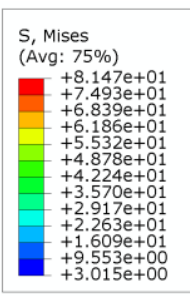

.

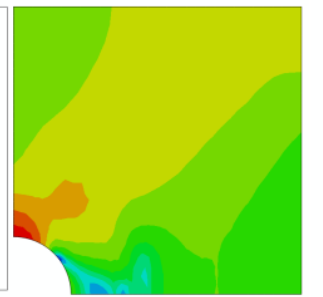

(b)

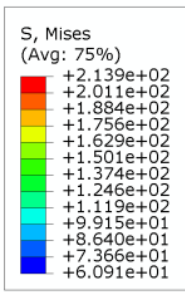

$+6.091 \mathrm{e}+01$ (c)

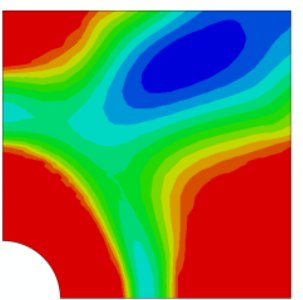

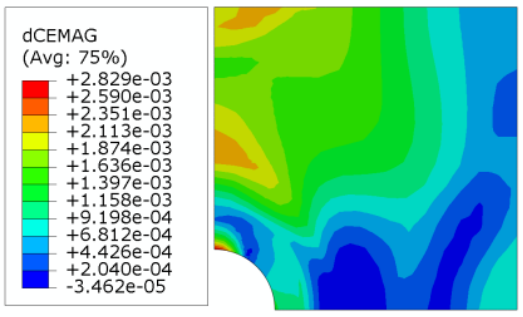

(d)

Figure 4 von-Mises stress [MPa] distribution at load case 1 for dwell time of $200 \mathrm{hrs}$ at the last loading cycle: (a) loading, (b) creep, (c) unloading, and (d) corresponding creep strain increment.

To understand the structural response of the plate, an element at the top of hole having both the peak stress and the peak creep strain is selected as a point of interest and then further investigations is carried out. Figure 5 illustrates curves of the creep stress relaxation and the creep strain increment against the dwell time with respect to the point of interest.

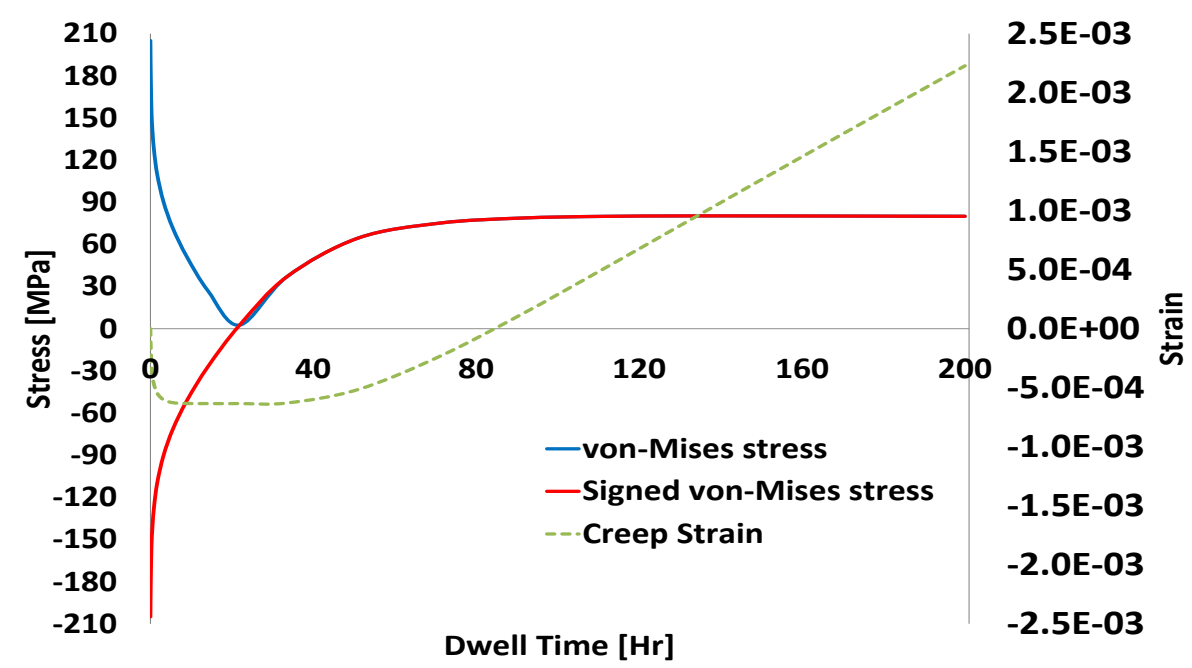

Figure 5 Creep stress relaxation curves and creep strain increment with load case 1 for dwell time of $200 \mathrm{hrs}$ at the point of interest. 
Significant creep stress relaxation can be seen with the signed von-Mises stress history in Figure 5. The relaxation proceeds from the start of creep stress of $-205 \mathrm{MPa}$ to the end of creep stress of 80MPa during the dwell. Mason et al. introduced the Rule of Sign for the Dominant Principal Direction. This rule suggests that the sign of the equivalent stress and strain is determined based on the dominant principal direction [20]. An investigation is carried out to select which principal stress component $\left(\sigma_{l}\right.$, $\sigma_{2}$, and $\sigma_{3}$ ) dominates each load instance; And in this paper for the holed plate the maximum principal stress shows the largest stress magnitude among the three principal components within a cycle. Hence, the algebraic sign of the von-Mises stress is determined by the sign of the maximum principal stress.

Further investigation shows the maximum principal stress is dominated by the stress component $\sigma_{11}$. Figure 6, which depicts stress distribution of the stress component $\sigma_{11}$ at the point of interest for each load instance, demonstrates similar stress values and identical sign to the signed von-Mises stress, which are summarized in Table 1 . Based on the observation, it is deduced that $\sigma_{11}$ may have a critical effect on the structural creep recovery mechanism as a dominant stress component.

Table 1 Stress history between signed von-Mises stress and stress component $\sigma_{11}$.

\begin{tabular}{cccc}
\hline Stress & Loading & Creep & Unloading \\
\hline Signed von-Mises[MPa] & -205 & 79.7 & 205 \\
$\sigma_{11}[\mathrm{MPa}]$ & -206.2 & 79.3 & 202.1 \\
\hline
\end{tabular}

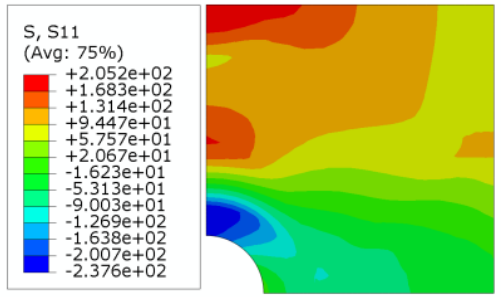

(a)

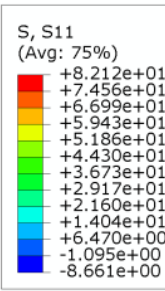

$-8.651 \mathrm{e}+00$

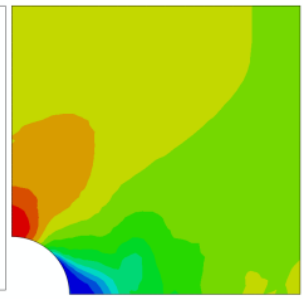

(b)
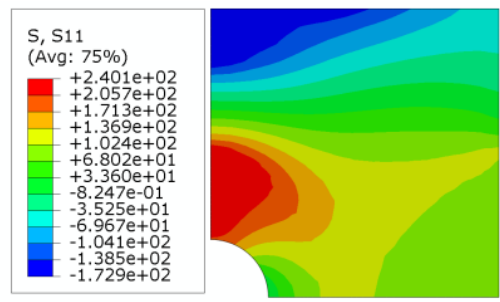

(c)

\section{Figure 6 Stress distributions[MPa] of the stress component $\sigma_{11}$ for each load instance with load case 1 for dwell time of 200hrs: (a) loading, (b) creep, (c) unloading.}

The structural creep recovery mechanism can be also identified with the creep strain curve. As shown in Figure 5, the creep strain increases rapidly with compressive creep stress during very early dwell stage. However, an increase of the compressive creep strain reaches steady state in the range of the creep stress from $-50 \mathrm{MPa}$ to $40 \mathrm{MPa}$, and afterwards tensile creep strain begins to grow until the end of dwell time. While the tensile creep strain increases it can be seen that the previous compressive creep strains are fully recovered during the dwell time of approximately $80 \mathrm{hrs}$. 
As shown the signed von-Mises stress history, the relaxation keeps the creep stress increased until it

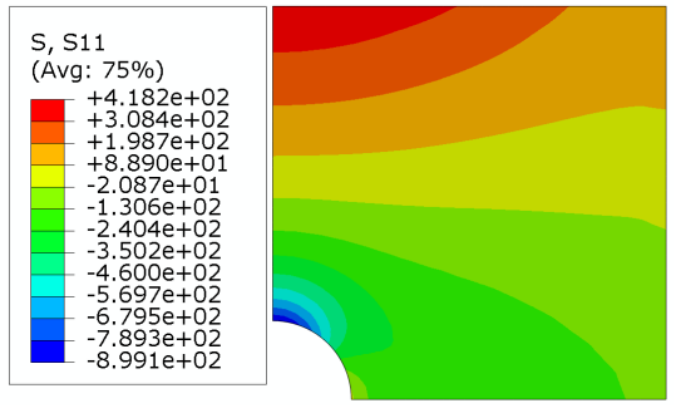

(a)

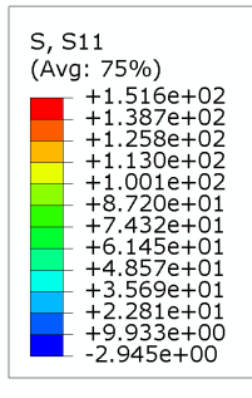

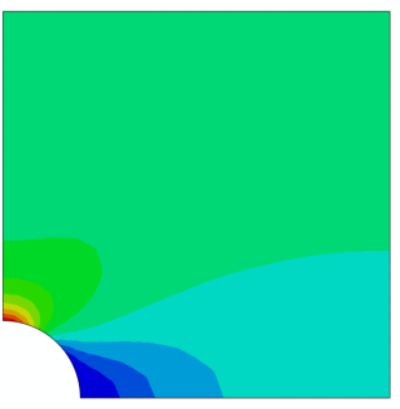

(b)

\section{Figure 7 Elastic stress solutions[MPa]: (a) stress component $\sigma_{11}$ from monotonic thermal gradient only with $\Delta \vartheta=0.7$ and (b) stress component $\sigma_{11}$ from monotonic mechanical load only with $\sigma_{p}=0.5 \sigma_{p o}$.}

Simultaneously, the creep strain grows with the dominant internal stresses, resulting in the creep strain recovery occurring within the dwell. The creep-cyclic plasticity response of the plate is illustrated as a saturated state of stress-strain cycles in Figure 8, where $\varepsilon$ is strain increment, subscripting of $L, B R, R, U$ denotes loading, before recovery, recovery, and unloading respectively, and superscripting of $e, c, p$ denotes elastic, creep, and plastic respectively. 
The structural creep recovery mechanism is also clearly distinguished in the hysteresis loop within the creep dwell. As noted, growing rate of the creep strain in the relaxation range from $-50 \mathrm{MPa}$ to $40 \mathrm{MPa}$ becomes steady state. The steady state of the creep rate does not signify the evolution of any creep strain, but it is attributed to a very small creep strain increment due to the small magnitude of creep stresses with the corresponding dwell time increment.

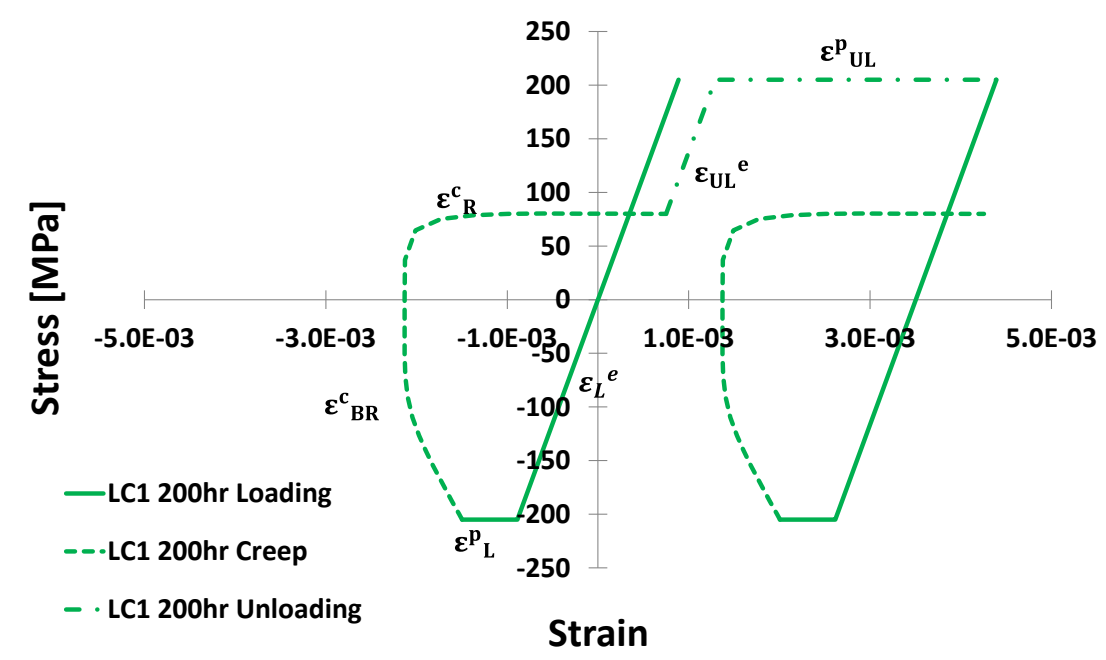

\section{Figure 8 Response of steady state stress-strain hysteresis loop corresponding to load case 1 for dwell time of $200 \mathrm{hrs}$.}

From these results, it has been confirmed that the structural creep recovery mechanism can be induced by the creep stress redistribution which causes the change of the dominant internal stresses within a creep dwell. In addition, it should be noted that the substantial creep stress relaxation accelerates the creep enhanced plasticity, which result in an increase of unloading plasticity, eventually leading to creep-ratchetting with every cycle. In order to fully understand the structural creep recovery mechanism, effects of varying dwell time and mechanical load level on the structural creep recovery mechanism will be analysed in the following parametric studies.

\subsection{Effect of Dwell Time and Load Level on the Structural Creep Recovery Mechanism}

To understand effects of dwell time on the structural creep recovery mechanism, $S B S$ analyses are performed with load case 1 for different dwell time of 10hrs, 50hrs, 100hrs, and 200hrs each. Nevertheless the peak creep strain occurs in different elements for different dwell time, the identical element to the point of interest is investigated due to the fact that maximum inelastic strain increment is observed at the concerning element. With respect to the point of interest, the analysis results are summarized in Table 2, where $\bar{\sigma}_{s}[M P a]$ and $\bar{\sigma}_{c}[M P a]$ are the start of creep stress and the end of 
creep stress respectively, $t$ and $t_{s}$ denote dwell time $[h r]$ and dwell time for the structural creep recovery to occur respectively. C.S.R is an abbreviation for the Creep Strain Recovery, and negative signs before the values in Table 2 represent the compressive stress or strain. The hysteresis loops at steady state for the dwell time of $100 \mathrm{hrs}$ and $200 \mathrm{hrs}$ each are depicted in Figure 9.

Table 2 Comparison key values and features with load case 1 for different dwell time.

\begin{tabular}{cccccccccc}
\hline$t$ & $\overline{\boldsymbol{\sigma}}_{\boldsymbol{s}}$ & $\overline{\boldsymbol{\sigma}}_{\boldsymbol{c}}$ & $\boldsymbol{\varepsilon}_{\boldsymbol{B} \boldsymbol{R}}^{\boldsymbol{c}}$ & $\boldsymbol{\varepsilon}_{\boldsymbol{R}}^{\boldsymbol{c}}$ & $\boldsymbol{\varepsilon}_{\boldsymbol{L}}^{\boldsymbol{P}}$ & $\boldsymbol{\varepsilon}_{\boldsymbol{U}}^{\boldsymbol{P}}$ & $\boldsymbol{t}_{\boldsymbol{s}}$ & $\mathrm{C} . \mathrm{S} . \mathrm{R}$ \\
\hline 10 & -205 & -42.86 & $-6.56 \mathrm{E}-04$ & - & $-6.10 \mathrm{E}-04$ & $2.23 \mathrm{E}-03$ & - & $\mathrm{N}$ \\
50 & -205 & 68.33 & $-6.34 \mathrm{E}-04$ & $8.78 \mathrm{E}-05$ & $-6.11 \mathrm{E}-04$ & $3.51 \mathrm{E}-03$ & $20 \sim 25$ & $\mathrm{Y}$ \\
100 & -205 & 80.56 & $-6.35 \mathrm{E}-04$ & $9.26 \mathrm{E}-04$ & $-6.11 \mathrm{E}-04$ & $3.48 \mathrm{E}-03$ & $20 \sim 21$ & $\mathrm{Y}$ \\
200 & -205 & 79.94 & $-6.34 \mathrm{E}-04$ & $2.88 \mathrm{E}-03$ & $-6.10 \mathrm{E}-04$ & $3.10 \mathrm{E}-03$ & $20 \sim 21$ & $\mathrm{Y}$ \\
\hline
\end{tabular}

In Table 2 we can see that the structural creep recovery starts at approximate time of $20 \mathrm{hrs}$. Hence, the structural creep recovery mechanism does not occur within the dwell time of 10hrs. For a dwell time of 50hrs, the compressive creep strain is still larger than the tensile creep strain. However, for a dwell time of $100 \mathrm{hrs}$, the tensile creep strain exceeds the compressive creep strain, resulting in the creep damage to be taken into account. For a dwell time of $200 \mathrm{hrs}$, more tensile creep strain is developed than 100 hrs. From this investigation, it can be deduced that dwell time may have effects on creep damage, provided that total dwell time $t$ is longer than $t_{s}$. However plastic strain increment at unloading remains a more or less same if the end of creep stress reaches to steady state regardless dwell time period.

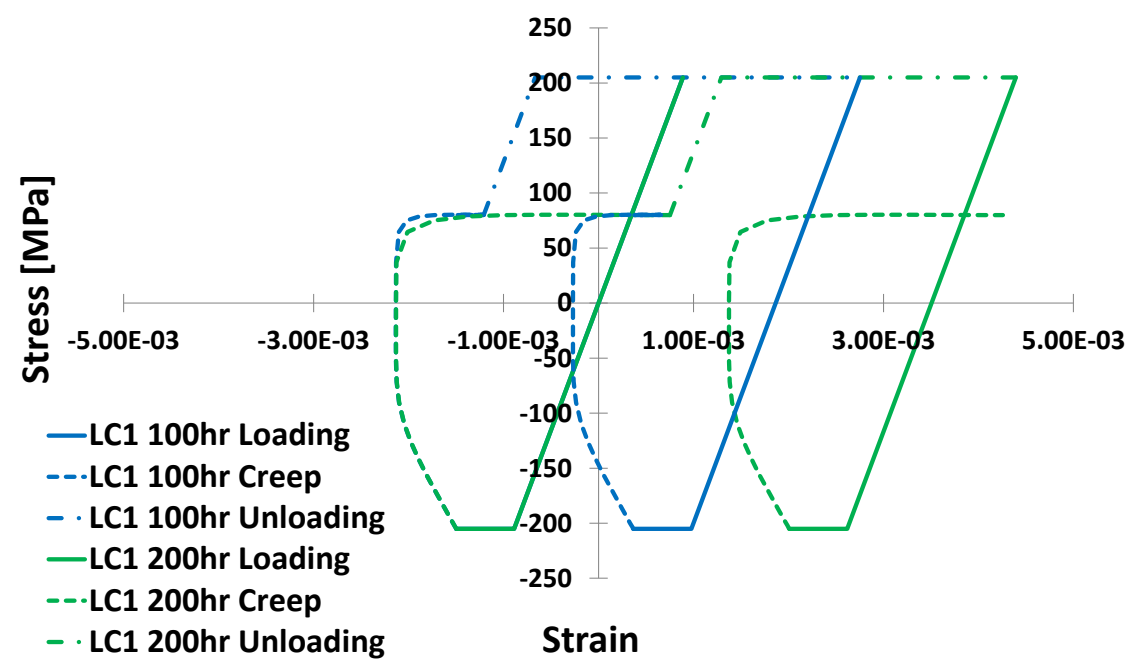

Figure 9 Response of steady state stress-strain loop corresponding to load case 1 for dwell time of $100 \mathrm{hrs}$ and $200 \mathrm{hrs}$ each. 
As explained in Section 3.1, the stress component $\sigma_{11}$ affects the significant stress relaxation. In order to evaluate the effects of the dominant stress component $\sigma_{11}$ on the structural creep recovery mechanism, another parametric study is carried out with varying uniaxial mechanical load level. Identical SBS analyses are performed for dwell time of $200 \mathrm{hrs}$ with three individual load cases which consist of identical and cyclic thermal load but the different magnitude of constant mechanical load; LC2 $\left(\Delta \theta=0.7\right.$ and $\left.\sigma_{p}=0.4 \sigma_{p 0}\right)$, LC3 $\left(\Delta \theta=0.7\right.$ and $\left.\sigma_{p}=0.1 \sigma_{p 0}\right)$, and LC4 $\left(\Delta \theta=0.7\right.$ and $\left.\sigma_{p}=0.7 \sigma_{p 0}\right)$ as shown in Figure 3.

Table 3 Comparison key values and feature for dwell time of $200 \mathrm{hr}$ with different mechanical load cases.

\begin{tabular}{ccccccccc}
\hline $\boldsymbol{L C}$ & $\overline{\boldsymbol{\sigma}}_{\boldsymbol{s}}$ & $\overline{\boldsymbol{\sigma}}_{\boldsymbol{c}}$ & $\boldsymbol{\varepsilon}_{\boldsymbol{B} \boldsymbol{R}}^{\boldsymbol{c}}$ & $\boldsymbol{\varepsilon}_{\boldsymbol{R}}^{\boldsymbol{c}}$ & $\boldsymbol{\varepsilon}_{\boldsymbol{L}}^{\boldsymbol{P}}$ & $\boldsymbol{\varepsilon}_{\boldsymbol{U}}^{\boldsymbol{P}}$ & $\boldsymbol{t}_{\boldsymbol{s}}$ & $\boldsymbol{C . S . \boldsymbol { R }}$ \\
\hline 1 & -205 & 79.94 & $-6.34 \mathrm{E}-04$ & $2.88 \mathrm{E}-03$ & $-6.10 \mathrm{E}-04$ & $3.10 \mathrm{E}-03$ & $14 \sim 21$ & $\mathrm{Y}$ \\
2 & -205 & 63.38 & $-7.65 \mathrm{E}-04$ & $4.88 \mathrm{E}-04$ & $-6.11 \mathrm{E}-04$ & $2.98 \mathrm{E}-03$ & $43 \sim 63$ & $\mathrm{Y}$ \\
3 & -205 & -36.86 & $-1.22 \mathrm{E}-03$ & - & $-6.23 \mathrm{E}-04$ & $1.83 \mathrm{E}-03$ & - & $\mathrm{N}$ \\
4 & -205 & 112.19 & $-4.19 \mathrm{E}-04$ & $1.89 \mathrm{E}-02$ & $-6.10 \mathrm{E}-04$ & $3.69 \mathrm{E}-03$ & $4 \sim 7$ & $\mathrm{Y}$ \\
\hline
\end{tabular}

From the analysis results, peak creep strain and inelastic strain of the three load cases occur at the identical element to the point of interest. Key values and features are listed in Table 3, and saturated hysteresis loops for the three load cases (LC1, LC2, and LC3) are depicted in Figure 10. Due to too large tensile creep strain, this hysteresis loop of LC4 is not plotted in Figure 10.

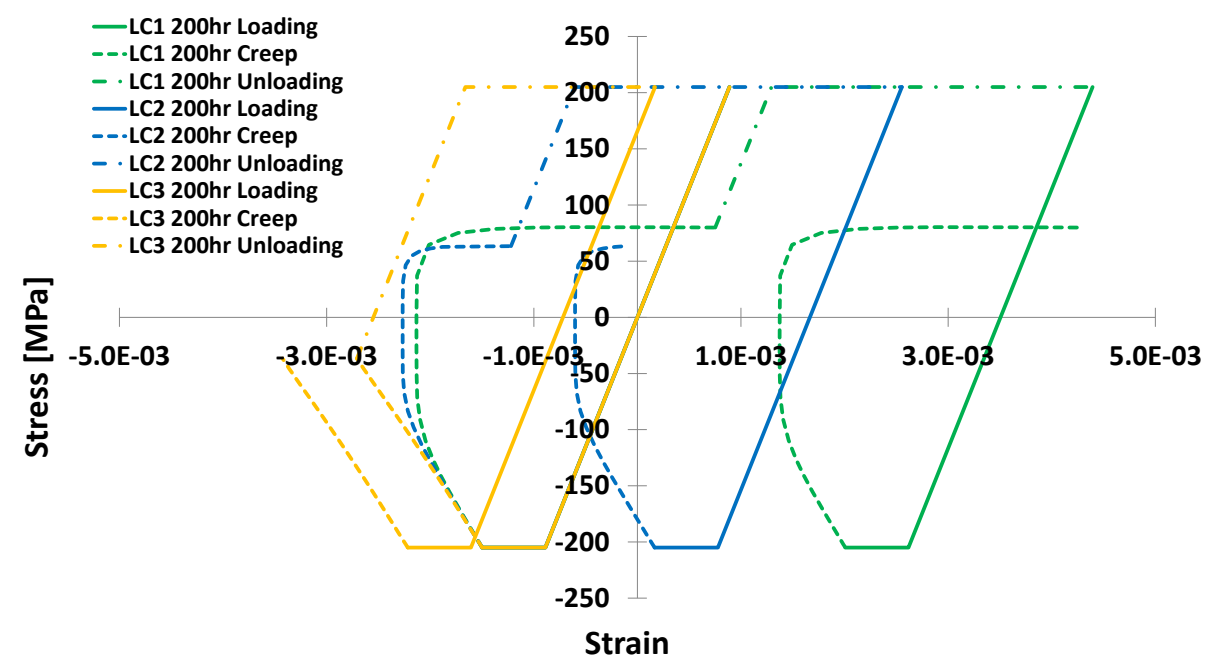

Figure 10 Response of steady state stress-strain loop corresponding to load cases 1,2 , and 3 for dwell time of 200hrs.

It can be seen in Table 3 that the end of creep stress is likely to reduce with a decrease of the mechanical load level. In other words, a degree of stress relaxation within a creep dwell is affected by 


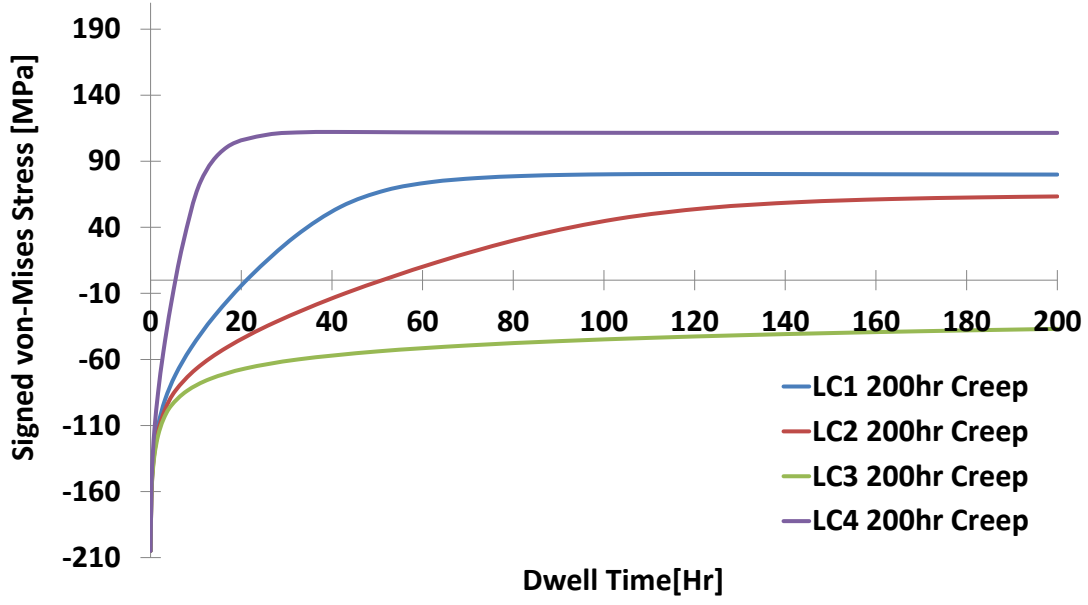

Figure 11 Creep stress relaxation curves for dwell time of $200 \mathrm{hrs}$ per load case.

Stress relaxation curves for each load case are illustrated with signed von-Mises stress in Figure 11. It can be seen that a degree of the stress relaxation increases with an increase of the mechanical load. The sign change of internal stresses take place early with the larger mechanical load. Interestingly, the structural creep recovery mechanism does not appear at load case 3 for dwell time of $200 \mathrm{hrs}$. This is because the secondary stress does not relax enough in order for the primary stress to become the dominant internal stress within the dwell time of 200hrs. In the numerical aspect, the secondary stresses can completely relax to zero stress in the case of the dwell time going to infinity. In other words, the structural creep recovery mechanism should be able to appear when the primary stresses acts in the opposite direction to the secondary stresses.

To verify this hypothesis, an $S B S$ analysis is performed with an identical load case to LC3 and extended dwell time of $60,000 \mathrm{hrs}$. The analysis result confirms the structural creep recovery mechanism occurring at dwell time of approximately 36,000hrs as shown in Figure 12. 


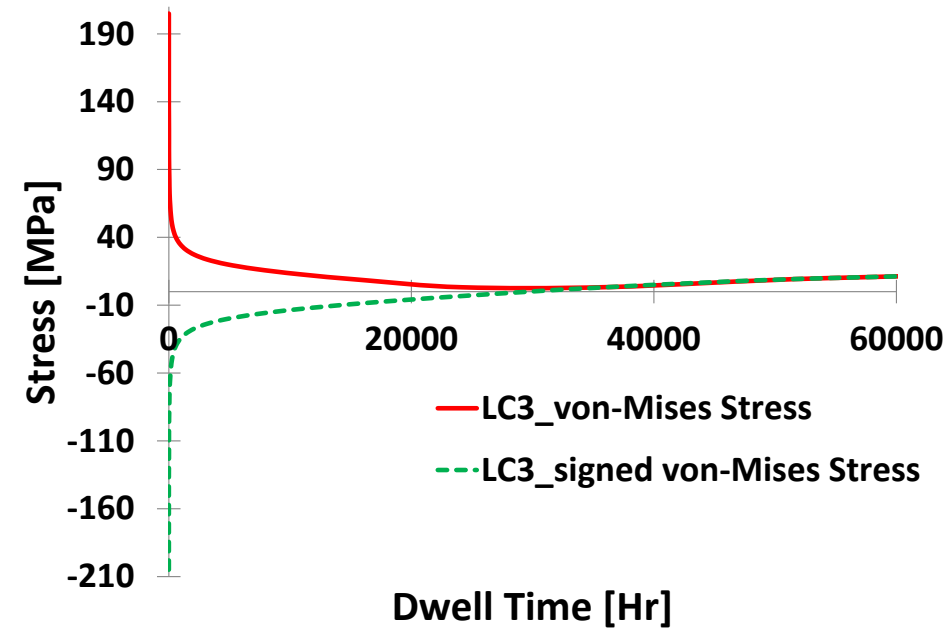

Figure 12 Creep stress relaxation curves in load case 3 for dwell time of $60,000 \mathrm{hrs}$.

From these parametric studies, it has been verified that a structure can experience the structural creep recovery mechanism under the specific loading condition and dwell period. In addition, variations of the tensile mechanical load have critical effects on the time $t_{s}$ and magnitude of the end of creep stress, which cause an increase of a total strain range.

The structural creep recovery mechanism has been identified with temperature independent material properties in the present section. However, strength of materials tends to decrease in the elevated temperature, whereas nonlinear creep behaviour is enhanced. In order to verify the structural creep recovery mechanism in practice, an additional parametric study with temperature dependent material parameters will be performed in the following section.

\subsection{Effect of Temperature Dependent Parameters on the Structural Creep Recovery Mechanism}

The temperature dependent material parameters of the SS316 are listed in Table 4. To implement temperature dependent creep properties, the Norton law is transformed to Eq.(3) by adopting the Arrhenius law, where $B$ is a frequency factor, $Q$ is an activation energy $\left[\mathrm{KJ}^{\prime} \cdot \mathrm{mol}^{-1}\right], R$ is the gas constant $\left[J \cdot \mathrm{mol}^{-1} \cdot K^{-1}\right]$, and $T$ represents temperature $[K]$ in Kelvin.

$$
\dot{\bar{\varepsilon}}^{c}=B \cdot \exp (-Q / R T) \bar{\sigma}^{n}
$$


The temperature dependent creep property, $B \cdot \exp (-Q / R T)$, in Eq.(3) is defined as the creep coefficient, $A$, in Table 4 . In order to implement significant high temperature creep behaviour, load case 5 consisting of cyclic thermal load $\left(\Delta \theta=1.4 \Delta \theta_{0}\right.$ and $\left.\theta_{0}=400^{\circ} \mathrm{C}\right)$ and constant mechanical load $\left(\sigma_{p}=0.7 \sigma_{p 0}\right)$ is created. A user subroutine is created to apply the temperature dependent material properties and to calculate corresponding equivalent creep strains. An SBS analysis is performed with load case 5 for dwell time of $200 \mathrm{hrs}$.

Table 4 Temperature dependent material parameters and creep material constants of the SS316.

\begin{tabular}{ccc}
\hline Temperature $\left[{ }^{\circ} \boldsymbol{C}\right]$ & Yield stress $[\mathbf{M P a}]$ & Creep coefficient, $\boldsymbol{A}$ \\
\hline 40 & 205 & $9.10 \mathrm{E}-43$ \\
100 & 170 & $2.95 \mathrm{E}-35$ \\
150 & 154 & $1.26 \mathrm{E}-30$ \\
200 & 144 & $5.67 \mathrm{E}-27$ \\
250 & 135 & $5.10 \mathrm{E}-24$ \\
300 & 129 & $1.40 \mathrm{E}-21$ \\
350 & 123 & $1.56 \mathrm{E}-19$ \\
400 & 118 & $8.67 \mathrm{E}-18$ \\
450 & 114 & $2.76 \mathrm{E}-16$ \\
500 & 110 & $5.60 \mathrm{E}-15$ \\
550 & 105 & $7.89 \mathrm{E}-14$ \\
600 & 100 & $8.22 \mathrm{E}-13$ \\
650 & 95 & $6.64 \mathrm{E}-12$ \\
700 & 90 & $4.33 \mathrm{E}-11$ \\
\hline
\end{tabular}

\begin{tabular}{ccccc}
\hline $\boldsymbol{B}$ & $\boldsymbol{Q}$ & $\boldsymbol{R}$ & $\boldsymbol{n}$ & $\boldsymbol{m}$ \\
\hline 46333.8 & 280 & 8.314 & 5 & 0 \\
\hline
\end{tabular}

From the analysis results, peak creep strain is observed at different element but maximum inelastic strain occurs at the same point of interest within a steady state cycle. Hence the identical point is selected as a critical element in order to investigate structural response. The key values and features are summarized in Table 5 and a saturated hysteresis loop for load case 5 is depicted in Figure 13.

Table 5 Key values and feature with load case 5 for dwell time of $200 \mathrm{hr}$.

\begin{tabular}{ccccccccc}
\hline $\boldsymbol{L C}$ & $\overline{\boldsymbol{\sigma}}_{\boldsymbol{S}}$ & $\overline{\boldsymbol{\sigma}}_{\boldsymbol{c}}$ & $\boldsymbol{\varepsilon}_{\boldsymbol{B} \boldsymbol{R}}^{\boldsymbol{C}}$ & $\boldsymbol{\varepsilon}_{\boldsymbol{R}}^{\boldsymbol{c}}$ & $\boldsymbol{\varepsilon}_{\boldsymbol{L}}^{\boldsymbol{P}}$ & $\boldsymbol{\varepsilon}_{\boldsymbol{U}}^{\boldsymbol{P}}$ & $\boldsymbol{t}_{\boldsymbol{s}}$ & $\boldsymbol{C} . \boldsymbol{S} . \boldsymbol{R}$ \\
\hline 5 & -90 & 17.6 & $-4.84 \mathrm{E}-04$ & $1.24 \mathrm{E}-02$ & $-1.20 \mathrm{E}-04$ & $1.64 \mathrm{E}-03$ & $2 \sim 3$ & $\mathrm{Y}$ \\
\hline
\end{tabular}

It can be seen that the structural creep recovery mechanism is identified as both compressive and tensile creep strains are developed within a dwell period. Unlike the analysis results of the temperature independent model with load case 1 , stress relaxation range is reduced but the recovery occurs at early dwell time of $t_{s}$, approximately $2.5 \mathrm{hrs}$, due to stress relaxation starting from the lower 
magnitude of the creep stress with the larger creep coefficient. Therefore, it develops smaller compressive creep strain than load case 1 . Moreover, the end of creep stress becomes steady state at stress level of $17.6 \mathrm{MPa}$ far lower than load case 1, despite higher tensile mechanical load to be applied than load case 1. As explained in Section 3.1, during creep stress redistribution, compressive creep stress increases up to the primary stress which is the rupture reference stress. Hence it can be presumed that the temperature dependent model has a lower reference rupture stress value. Tensile creep strain of load case 5 is larger than four times of load case 1 due to higher creep coefficient and longer tensile dwell within the recovery.

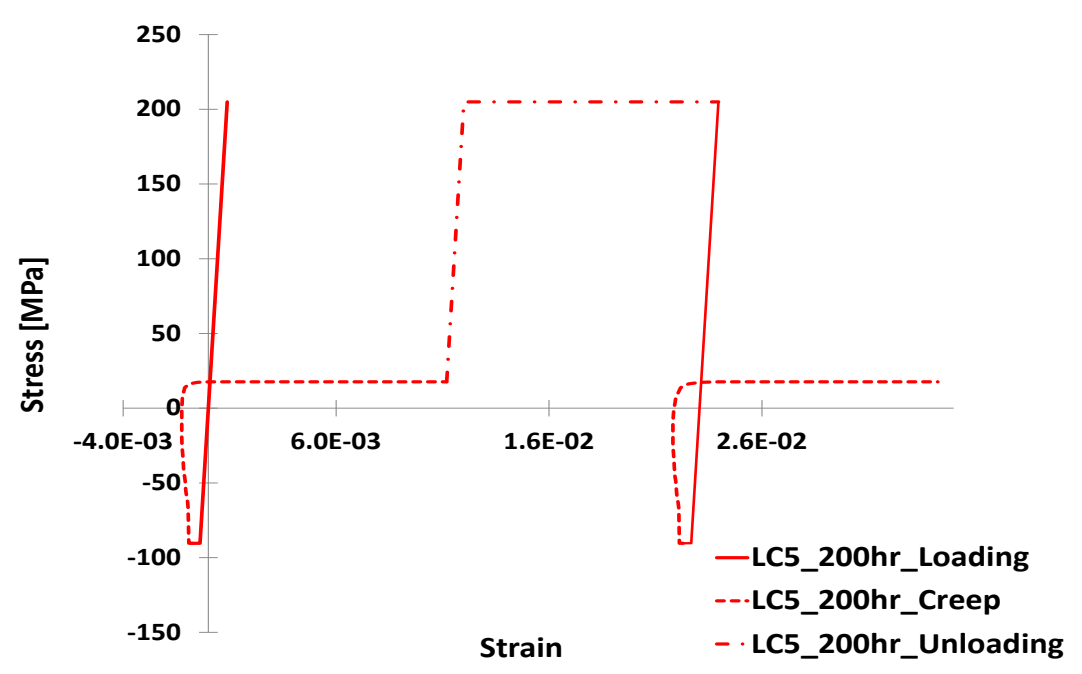

\section{Figure 13 Response of steady state stress-strain loop corresponding to load case $\mathbf{5}$ for dwell time of $200 \mathrm{hrs}$.}

From this study, it has confirmed that the structural creep recovery mechanism requires consideration for the temperature dependent cases under the specific loading condition in the elevated temperature.

\subsection{Effect of Practical Hardening Parameters on the Structural Creep Recovery Mechanism}

In this section, creep-cyclic plasticity of the holed plate is analysed by applying mechanical properties of a low carbon grade 316 stainless steel with Chaboche hardening model at $600^{\circ} \mathrm{C}$. To validate the structural creep recovery mechanism, isothermal cyclic testing data has been used for the simulation. The testing data is taken from a literature [21].

For isotropic hardening, the yield surface size $\sigma^{0}$ can be defined as initial yield surface size $\sigma_{y}$ approaches to saturated constant value $R$ which can be expressed by maximum change in the size of 
For kinematic hardening, the hardening law is composed of several kinematic hardening components which are back stresses $X_{k}$ and the overall back stress $\mathrm{X}$ can be calculated by summation of each back stress, where $n$ is the number of back stress. $C_{k}$ and $\alpha_{k}$ denote material constants which can be calibrated from experiment data. To obtain Chaboche model parameters, two back stresses are considered and corresponding material constants are calibrated by fitting the stabilized hysteresis loop from experiments [21]. The employed material properties are listed in Table 6.

$$
\begin{gathered}
\dot{\mathrm{X}}_{k}=C_{k} \frac{1}{\sigma^{0}}(\sigma-\mathrm{X}) \dot{\bar{\varepsilon}}^{p}-\alpha_{k} \mathrm{X}_{k} \dot{\bar{\varepsilon}}^{p} \\
\mathrm{X}=\sum_{k=1}^{n} \mathrm{X}_{k}
\end{gathered}
$$

Table 6 Material properties for the simulation.

\begin{tabular}{ccccccccc}
\hline $\boldsymbol{T}\left[{ }^{\circ} \mathrm{C}\right]$ & $\boldsymbol{E}[\mathrm{GPa}]$ & $\sigma_{y}[\mathrm{MPa}]$ & $Q_{\infty}[\mathrm{MPa}]$ & $\boldsymbol{b}$ & $\boldsymbol{C}_{1}$ & $\boldsymbol{C}_{2}$ & $\boldsymbol{\alpha}_{1}$ & $\boldsymbol{\alpha}_{2}$ \\
\hline 600 & 149.69 & 205 & 62.26 & 42.45 & 30211.65 & 4677.23 & 589.56 & 80.53 \\
\hline
\end{tabular}

To verify the Chaboche model, stress-strain hysteresis loops are generated by FE simulations under strain-controlled symmetric cyclic loading with a strain amplitude of $0.6 \%$. The numerical simulation results are compared to an experiment result for the isothermal cyclic test results at $600^{\circ} \mathrm{C}$, which agree with the experiment result as shown in Figure 14. 
Figure 14 Cyclic test result at $600^{\circ} \mathrm{C}[21]$ and simulation result, $\Delta \varepsilon= \pm 0.6 \%$.

For creep behaviour, the Norton-Bailey time hardening law is used with the following material constants: $A=5.604 \times 10^{-15} h^{-1}$ at $600^{\circ} \mathrm{C}, n=5.769$, and $m=-0.55$. Cyclic thermal load $\left(\Delta \theta=1.2 \Delta \theta_{0}\right.$ and $\left.\theta_{0}=300^{\circ} \mathrm{C}\right)$ and constant mechanical load $\left(\sigma_{p}=0.5 \sigma_{p 0}\right)$ are created as load case 6 for the analysis. The thermal conductivity and expansion coefficient used for the simulation are $21.5[\mathrm{~W} / \mathrm{mK}]$ and 1.75 x $10^{-5}\left[{ }^{\circ} C^{-1}\right]$ respectively. An $S B S$ analysis with the combined hardening parameters is performed under load case 6 for dwell time of $10 \mathrm{hrs}$.

Table 7 Key values and feature at the initial cycle and saturated cycle with load case 6 for dwell time of $10 \mathrm{hr}$.

\begin{tabular}{ccccccccc}
\hline $\boldsymbol{L C}$ & $\bar{\sigma}_{s}$ & $\bar{\sigma}_{c}$ & $\varepsilon_{B R}^{c}$ & $\varepsilon_{R}^{c}$ & $\varepsilon_{L}^{p}$ & $\varepsilon_{U}^{p}$ & $t_{s}$ & Cycle \\
\hline \multirow{2}{*}{6} & -239 & 79 & $-7.43 \mathrm{E}-04$ & $2.71 \mathrm{E}-03$ & $-7.84 \mathrm{E}-04$ & $2.04 \mathrm{E}-03$ & 0.01 & $1^{\text {st }}$ \\
& -180 & 78 & $-6.45 \mathrm{E}-04$ & $1.19 \mathrm{E}-03$ & $-2.13 \mathrm{E}-04$ & $2.79 \mathrm{E}-03$ & 0.5 & $10^{\text {th }}$ \\
\hline
\end{tabular}

Table 7 presents key values from the simulation results. The analysed data shows that the structural creep recovery mechanism occurs with the Chaboche hardening parameters. Unlike the previous case studies, the peak creep strain does not occur at the concerning location but the maximum inelastic strain still takes place. This means that the structural creep recovery mechanism affect structural integrity with fatigue damage rather than creep damage.

Figure 15 exhibits stress-strain hysteresis loops in transition from the first cycle to the stabilized cycle. As shown the cyclic hardening in Figure 14, the saturated hysteresis loop at $10^{\text {th }}$ cycle has higher maximum stress than the first cycle. Due to asymmetric cyclic loading applied to the structure, the hysteresis loops shows ratchetting response in transition to tensile direction as cycle goes. 
Consequently, smaller loading plasticity is observed at the saturated cycle but its unloading plasticity is larger than the first cycle. Short time of $t_{s}$ affects creep strain increment as both the first and the last cycle accumulates small compressive creep strain before structural creep recovery occurs, in particular the saturated cycle develops smaller than the first cycle due to the relaxation starting from lower stress in magnitude. The first cycle develops larger creep strain than the saturated cycle at similar level of the end of the creep stress within the recovery. This is because the dwell time of the first cycle at the recovery is longer than the saturated cycle.

From this investigation it is confirmed that the structural creep recovery mechanism can occur with the real hardening model. The cyclic hardening results in the saturated loop moves up with $Q_{\infty}$ in tension from the first cycle. Assuming the same transition of the cyclic response, it can be expected that cyclic hardening may prevent the structural creep recovery mechanism if the saturated cycle is formed in the tensile domain by increasing of $Q_{\infty}$. However, despite the structural creep recovery mechanism could disappear, creep ratchetting still remains due to either creep strain or unloading plasticity.

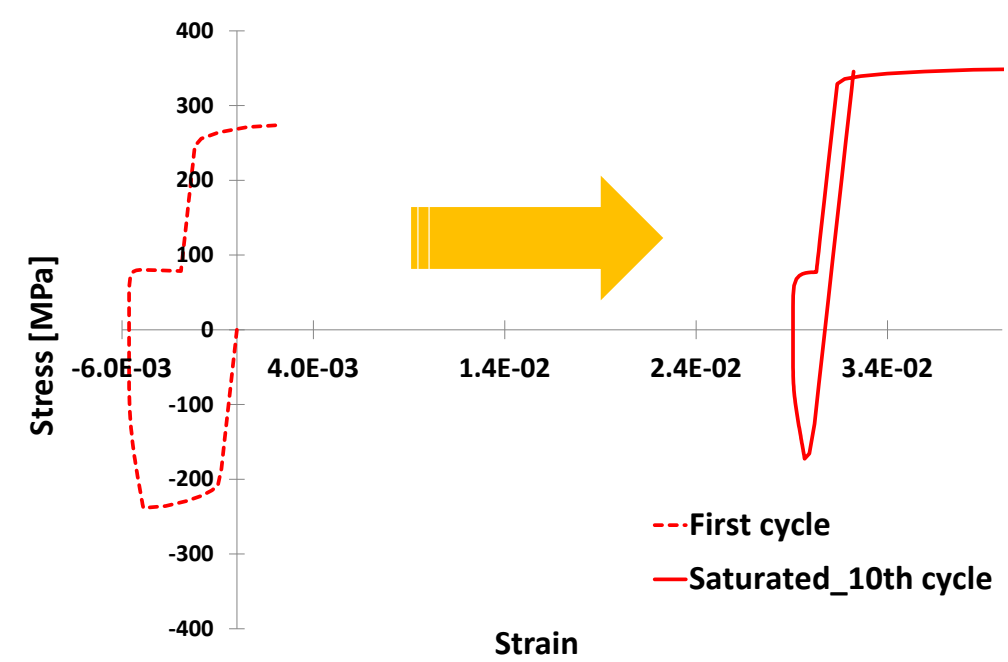

\section{Figure 15 Structural responses in transition from the first cycle to the saturated cycle at $10^{\text {th }}$ cycle for load case 6.}

\section{Discussions}

\subsection{Practical Problems Involving the Structural Creep Recovery Mechanism}

As demonstrated in Section 3.1, when a structure is subjected to a specific loading condition, the mechanical load that produces the primary stress acting in the opposite direction to the secondary stress can lead to the creep stress redistribution in the structure within a creep dwell. The creep stress 
redistribution can result in the conversion of the dominant internal stresses which induces the structural creep recovery mechanism will appear in every operating cycle, which results in negatively affecting the lifetime of the structure with an increase of the total strain range as shown in the previous studies. Hence, it is worthwhile examining practical problems, which may have additional potential risks regarding this mechanism.

Components in non-isothermal conditions can be found in forced cooling systems using either air flow or coolant equipment. For example, internal combustion chambers are equipped with forced cooling systems due to the exposure to high temperature and pressure in operation. Mechanical components comprising the combustion chamber are cylinder liner, piston crown, and valves. It has been reported that cracking or fractures with excessive plastic deformation including the creep are known issues in these components $[22,23]$. High temperature heat exchangers can be another practical problem exposing to potential risk, with the thermal gradient between inlet and outlet lines. Thus, steel casings or structures holding tubes or fins are likely vulnerable parts to thermal fatigue damage considering the structural creep recovery mechanism. Moreover, a metal matrix composite (MMC) material in the elevated temperature may experience the similar problem. Due to the different coefficients of thermal expansion of the two materials, thermally induced internal stresses can be placed on the edges of the metal matrix phase even at isothermal condition. To avoid the hidden risk, material selection and life assessment of the components are very important.

\subsection{Limitations of the Elastic Follow-up Factor in the Structural Creep Recovery Mechanism}

Elastic follow-up is a term to describe the creep strain accumulation in a local region where resulting in evolution of the total strain but majority regions are remains elastic behaviours [5]. The relationship between creep stress relaxation and creep strain accumulation shows non-linear behaviour and can be simplified by using the elastic follow-up as shown in Eq.(9), where $Z$ is the elastic follow up-factor.

$$
\frac{d \bar{\varepsilon}^{c}}{d t}+\frac{Z}{\bar{E}} \cdot \frac{d \bar{\sigma}}{d t}=0
$$

The $\mathrm{Z}$ can be defined as a ratio of creep strain increment to elastic strain increment during a creep dwell as Eq.(10) and can be depicted as Figure 16, where $\Delta \bar{\varepsilon}_{T o t}$ denotes total strain increment, $\Delta \bar{\sigma}$ is von-Mises equivalent stress drop within a dwell, $\Delta \bar{\varepsilon}^{c}$ is creep strain increment, and $\Delta \bar{\varepsilon}^{e}$ is elastic strain increment. 


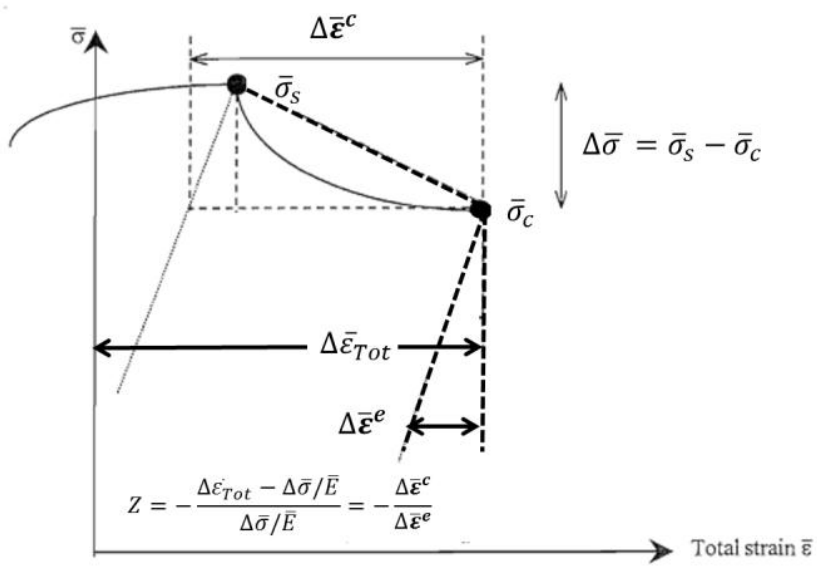

Figure 16 Definition of general elastic follow-up factor $Z$.

As a conservative approximation, the creep strain increment is taken into account by multiplying a scalar value of the $\mathrm{Z}$ to the elastic strain increment in a range of the creep stress drop instead of solving the non-liner relationship. However, the elastic follow-up factor cannot be applied to the structural creep recovery mechanism. As shown the hysteresis loops in Section 3, the stress relaxations take place in both compressive and tensile domains within a dwell. Thus, creep strain should not be predicted by using an elastic follow-up factor. Moreover, a formula for a forward creep law to estimate creep stress relaxation against dwell time for an arbitrary value of the elastic followup factor will not work either. The formula can be presented as Eq.(11), where $\bar{E}=3 E / 2(1+v)$ which is an effective elastic modulus.

$$
\bar{\sigma}_{c}=\left\{\bar{\sigma}_{s}^{-n+1}+\frac{1}{Z}\left(\frac{n-1}{m+1}\right) A \bar{E} \Delta t^{m+1}\right\}^{\frac{-1}{n-1}}
$$

Hence, it is not recommended to predict neither creep strain with a value of $\mathrm{Z}$ nor the end of creep stress with the formula, if a structure experiences the structural creep recovery mechanism.

\subsection{Structural Integrity Assessment in the Presence of the Structural Creep Recovery Mechanism}

Ratchetting is the cyclic accumulation of the inelastic strain with non-zero mean stress amplitude. In the creep regime, the ratchetting should take into account cyclic accumulation of both plastic strain 
and creep strain. The design codes and assessment procedures propose to assess the plastic ratchetting and creep ratchetting separately [5]. From the numerical results the holed plate exhibits creep ratchetting mechanism. Two key factors that cause the creep ratchetting are dwell time and primary load level. The dwell time has a significant effect on the creep strain accumulation, where it is referred to as "cyclically enhanced creep". The primary load level determines the magnitude of the creep stress relaxation, which affect the accumulation of the unloading plastic strain, where it is referred to "creep enhanced plasticity". For the cyclically enhanced creep, effects of creep strain on the structural integrity may not be significant due to the structural creep recovery, otherwise, for the creep enhanced plasticity, the stress relaxation affects the unloading plasticity substantially, causing the enhancement in total strain range within a cycle. Therefore it is expected that the creep ratchetting may appear in the most case when a structure experiences the structural creep recovery mechanism. However, although creep ratchetting response occurs, it should be evaluated which damage is the most critical to structural integrity among creep damage, fatigue damage, and ratchetting damage. In this regards, we want to suggest appropriate evaluation manners for creep-fatigue damage calculation if a structure does not fail due to ratchetting in the presence of the structural creep recovery mechanism.

Several creep-fatigue damage calculation methods have been introduced in the high temperature design codes such as ASME Section III, RCC-MR, and R5. However, these standard methods may not always provide accurate predictions for the damage against variation of the dwells and the stress states within the cycle. Spindler[6] introduced an improved method for calculation of creep damage using test results from three austenitic stainless steels. The stress modified creep ductility exhaustion method proved to predict more accurate result than time fraction method in alteration of the stress states and the dwells. Based on the claims, our evaluation methods are extended from the latest approaches introduced by R5.

In $\mathrm{R} 5$, a linear damage summation method is used to calculate creep and fatigue damage, which can be defined by Eq.(12), where $D_{c}$ and $D_{f}$ are creep damage and fatigue damage respectively. If the sum of the damages is greater and equal than 1 , failure will occur.

$$
D_{c}+D_{f} \leq 1
$$

The fatigue damage per cycle, $d_{f}$, in R5 can be expressed as Eq.(13), where $N_{0}$ is number of fatigue cycle to create a crack of depth $a_{0}$ at the total strain range $\Delta \varepsilon_{T}$ and temperature $T$.

$$
d_{f}=1 / N_{0}\left(\Delta \varepsilon_{T}, T\right)
$$


The creep damage per cycle, $d_{c}$, is able to be estimated using the stress modified ductility exhaustion $(S M D E)$ approach in $\mathrm{R} 5$, defined by:

$$
d_{c}^{S M D E}=\int_{o}^{t} \frac{\dot{\bar{\varepsilon}}^{c}}{\varepsilon_{f}\left(\dot{\bar{\varepsilon}}^{c}, \bar{\sigma}, T\right)} d t
$$

where $t$ is the dwell time, $t_{f}$ is the creep rupture time which is a function of stress and temperature, and $\varepsilon_{f}$ is creep ductility of a material which is a function of the instantaneous creep strain rate at a given temperature. If the function of $\varepsilon_{f}$ includes both stress and the creep strain rate, it implies the SMDE approach.

To evaluate creep-fatigue damage of the structural creep recovery mechanism, the healing effect of compressive dwell needs to be considered for austenitic stainless steel [24]. The effect demonstrates that the sintering of creep cavities under compressive creep stress may be able to compensate the creep damage cumulated under tensile creep stress. Three critical dwell time increments need to be distinguished in order to apply the healing effect to the structural creep recovery mechanism, which are: time for the stress relaxation being reversed in sign $\left(t_{s}\right)$, time for creep strains being fully recovered $\left(t_{r}\right)$, and end of dwell time $(t)$.

For dwell time of $t_{s}$, creep damage in a tensile sign domain needs to be taken into account, whereas it could be negligible in a compressive sign domain due to the fact that creep cavity cannot nucleate. In addition, fatigue damage will increase within a cycle due to the end of creep stress becoming zero. For dwell time of $t_{r}$, identical tensile creep strain is accumulated to compressive creep strain within the dwell, accumulating physically zero creep strain. Hence, it is suggested that enhanced fatigue damage needs to be calculated without any creep damage. For dwell time beyond $t_{r}$ and up to the end of dwell time $t$, creep damage in a tensile domain after the time of $t_{r}$ requires consideration along with fatigue damage corresponding to total strain range, otherwise only the fatigue damage to be considered without any creep damage in a compressive domain.

When it comes to the holed plate problem, with the creep dwell starting from a compressive stress, it is suggested that creep damage within the time increment from $t_{r}$ to $t$ only requires consideration, and Eq.(13) can be used for fatigue damage calculation affiliated with total strain range in view of the healing effect and a direction of creep-ratcheting heading to tensile. On the contrary, if it is starting from a tensile stress, creep damage needs to be considered only within dwell time of $t_{s}$, otherwise creep damage within a cycle can be negligible, if the dwell time beyond $t_{s}$. Within dwell time of $t_{r}$, Eq.(13) is still applicable to fatigue damage calculation. However, for dwell time of $t$, the fatigue damage should be enhanced by changing $N_{0}$ to $N_{g}$ in Eq.(13) considering a direction of the creepratchetting moving to compressive, where $N_{g}$ is the number of cycles to grow a fatigue crack from 
$0.02 \mathrm{~mm}$ to $a_{0}[5]$. This is because it is reasonable for the nucleation phases to be removed under compressive stress.

\section{Conclusions}

The structural creep recovery mechanism has been identified within a peak dwell by finite element analysis of a 3D holed plate subjected to cyclic thermal load and constant mechanical load. From the analysis results, it is observed at loading that the combined thermo-mechanical load imposes the compressive secondary stress and tensile primary stress on the plate. Due to the primary stress acting in the opposite direction to the secondary stress, the assessment point of the plate experiences significant stress relaxation as the sign of the creep stress is reversed within a dwell due to creep stress redistribution. As a result, compressive and tensile creep strains are developed sequentially during creep dwell, leading to structural creep strain recovery.

Parametric studies have proved that structural creep recovery is a possible mechanism within a creep dwell, provided that the secondary stress dominates the primary stress at the assessment point when loading. It has been shown that the constant mechanical load level has effects on time for recovery to occur and a magnitude of the end of creep stress. The structural creep recovery mechanism has been valid by numerical investigations using practical material properties such as temperature dependent mechanical properties, Chaboche hardening model, and Norton-Bailey creep parameters.

Potential risks associated with this mechanism could be accounted for high temperature components equipped with a forced cooling system and MMC materials that have different thermal coefficients of expansion. If a structure experiences the structural creep recovery mechanism, the classical elastic follow-up factor and the formula Eq.(11) are not applicable to predicting the creep strain accumulation and the end of creep stress respectively. In the presence of the structural creep recovery mechanism, we suggest creep-fatigue damage evaluation methods that creep damage should be reduced or neglect for a dwell in which either physically zero creep strains or compressive creep strains are larger than tensile creep strain, considering the healing effect of austenitic stainless steel. On the other hand, fatigue damage tends to increase due to significant creep enhanced plasticity. In particular, when the compressive creep dwell is dominant within a cycle, the fatigue damage should be further enhanced by replacing $N_{0}$ with $N_{g}$. Consequently, the structural creep recovery mechanism causes significant unloading plasticity which affects the structural integrity with enhanced fatigue damage. 


\section{Acknowledgement}

The authors gratefully acknowledge the support of the University of Strathclyde and East China

University of Science and Technology during the course of this work. Supports from National Science Foundation of China (51605165, 51475167), National Key Research and Development Program of China (2016YFC0801905), and the '111 project' are also greatly acknowledged.

\section{References}

1. Zinkle, S.J. and G. Was, Materials challenges in nuclear energy. Acta Materialia, 2013. 61(3): p. 735-758.

2. Viswnathan, R. An overview of failure mechanisms in high temperature components in power plants. in ICF10, Honolulu (USA) 2001. 2013.

3. Sabharwall, P., S.M. Bragg-Sitton, and C. Stoots, Challenges in the development of high temperature reactors. Energy Conversion and Management, 2013. 74: p. 574-581.

4. Skelton, R., Crack initiation and growth during thermal transients, in Component Reliability under Creep-Fatigue Conditions. 1998, Springer. p. 17-86.

5. Ainsworth, R.A. and R5_Panel, Assessment procedure for the high temperature response of structures, in EDF Energy Nuclear Generation Ltd. 2014.

6. Spindler, M., An improved method for calculation of creep damage during creep-fatigue cycling. Materials Science and Technology, 2007. 23(12): p. 1461-1470.

7. White, P. The fast reactor state variable model for cyclic inelastic analysis of type 316 stainless steel. in Transactions of the 12. international conference on Structural Mechanics in Reactor Technology (SMiRT). Volume L: Inelastic behaviour of solids and structures. 1993.

8. Miller, D., C. Hamm, and J. Phillips, A mechanistic approach to the prediction of creepdominated failure during simultaneous creep-fatigue. Materials Science and Engineering, 1982. 53(2): p. 233-244.

9. A Fookes, S.X.L., D J Smith, and M W Spindler, Stress Relaxation during Dwells for Creep and Fatigue Cycling of Type $316 \mathrm{H}$ Stainless Steel at $550^{\circ} \mathrm{C}$, in 2nd Int. ECCC Conf., Creep \& Fracture in High Temperature Components - Design \& Life Assessment. 2009.

10. Bolton, J., The consequences of recovery for the analysis of creep in steel structures. International Journal of Pressure Vessels and Piping, 2010. 87(5): p. 266-273.

11. Boyle, J.T. and J. Spence, Stress analysis for creep. 2013: Elsevier.

12. Cho, N.-K. and H. Chen. Investigation of structural creep strain recovery and its impact on structural integrity. in 24th International Conference on Structural Mechanics in Reactor Technology. 2017.

13. Chaboche, J.-L., Constitutive equations for cyclic plasticity and cyclic viscoplasticity. International journal of plasticity, 1989. 5(3): p. 247-302.

14. Chaboche, J.-L., On some modifications of kinematic hardening to improve the description of ratchetting effects. International journal of plasticity, 1991. 7(7): p. 661-678.

15. Lemaitre, J. and J.-L. Chaboche, Mechanics of solid materials. 1994: Cambridge university press.

16. Chen, H. and A.R. Ponter, Shakedown and limit analyses for 3-D structures using the linear matching method. International Journal of Pressure Vessels and Piping, 2001. 78(6): p. 443451.

17. Ponter, A.R. and H. Chen, A minimum theorem for cyclic load in excess of shakedown, with application to the evaluation of a ratchet limit. European Journal of Mechanics-A/Solids, 2001. 20(4): p. 539-553. 
18. Dean, J., et al., A procedure for extracting primary and secondary creep parameters from nanoindentation data. Mechanics of Materials, 2013. 65: p. 124-134.

19. Jin, S., H. Harmuth, and D. Gruber, Compressive creep testing of refractories at elevated loads-Device, material law and evaluation techniques. Journal of the European Ceramic Society, 2014. 34(15): p. 4037-4042.

20. Manson, S. and G.R. Halford, Fatigue and durability of metals at high temperatures. 2009: ASM International.

21. Gong, Y., et al., Determination of material properties in the Chaboche unified viscoplasticity model. Proceedings of the Institution of Mechanical Engineers, Part L: Journal of Materials: Design and Applications, 2010. 224(1): p. 19-29.

22. Fakaruddin, M.A., A.M. Hafiz, and K. Karmegam, MATERIALS SELECTION FOR WET CYLINDER LINER. IOSR Journal of Engineering (IOSRJEN) e-ISSN, 2012: p. 2250-3021.

23. GONERA, M. and O. SANDIN, Thermal Analysis of a Diesel Piston and Cylinder Liner using the Inverse Heat Conduction Method.

24. Wells, C. and C. Sullivan, Interactions between creep and low-cycle fatigue in Udimet 700 at $1400 \mathrm{~F}$, in Fatigue at high temperature. 1969, ASTM International. 